\title{
Forest Measurements Using ICESat- Geoscience Laser Altimeter System -A Review
}

\author{
Indu Indirabai ${ }^{1 *}$, M.V. Harindranathan Nair ${ }^{2}$, Jaishankar. R. Nair ${ }^{3}$, Rama Rao Nidamanuri ${ }^{4}$ \\ ${ }^{1,2}$ School of Environmental Studies, Cochin University of Science \& Technology, Kochi, Kerala, India ${ }^{1,2}$. \\ ${ }^{3}$ C.V Raman Laboratory of Ecological Informatics, IIITM-Kerala, Thiruvananthapuram, Kerala, India ${ }^{3}$ \\ ${ }^{4}$ Department of Earth \& Space Sciences, Indian Institute of Space Science and Technology, \\ Thiruvananthapuram, Kerala, India 4 . \\ *Corresponding author: indupvm@gmail.com
}

\begin{abstract}
Forests play a vital role in carbon cycle and in maintaining climate balance. The measurement of three dimensional forest structural attributes has a profound impact on the forest ecosystem management. Active remote sensing systems provide the capability to quantify the three dimensional structural of forests by measuring both the vertical as well as horizontal structure of forests. Vertical forest measurements can be directly and accurately estimated by means of the space borne Light Detection and Ranging (LiDAR) and it has been often used to estimate the forest structural attributes. This paper provides an introductory review of application of the Geoscience Laser Altimeter System (GLAS) onboard NASA's Ice Cloud and Land Elevation Satellite (ICESat), for the three dimensional structural attribute measurements of forests. The review attempted to briefly explain the characteristics of ICESat/GLAS instruments, data processing and certain applications from the wide range of applications of GLAS data in forestry.
\end{abstract}

Index Terms: Forests, Structural measurements, ICESat, GLAS, Space borne Laser Altimetry.

\section{INTRODUCTION}

Precise monitoring of the forest distribution and biomass are very essential to understand the global carbon cycle. Traditional field based forest inventories are constrained by high expense and extensive time requirements. Even though the passive optical remote sensing technologies (both multispectral and hyper spectral) have the ability to cover large forest areas but are limited by their inability to provide the vertical three dimensional structure of forest. Light Detection and Ranging (LiDAR), an active remote sensing technology can successfully measure both the vertical as well as horizontal distribution of forests very accurately. The airborne LiDAR systems available can cover only limited area and are found to be very expensive, and the data processing requires a lot of time. Therefore, space borne LiDAR systems play an important role since it can cover large areas for the three dimensional structural measurements of forests.

The review focuses on the potential of satellite Light Detection and Ranging (LiDAR) for the retrieval and measurement of forest structural attributes. Review highlights the application of ICESat /GLAS in the three dimensional measurements of forests and their support in ecosystem and climate modelling.

\section{ICESat}

Geoscience Laser altimeter system (GLAS), a new generation space borne LiDAR onboard Ice Cloud and Land Elevation Satellite (ICESat) launched by National Aeronautics and Space Administration (NASA). GLAS was originally designed for ice elevation monitoring. Its primary objective is to measure long term polar ice changes and additional scientific objectives were obtaining global measurements of sea ice land vegetation oceans, forest canopy heights, land terrain changes and distribution of clouds and aerosols. [1], [2]. It can be used for vegetation analysis since it can offer global estimates of canopy height. The ICESat satellite is given in the Figure 1. 


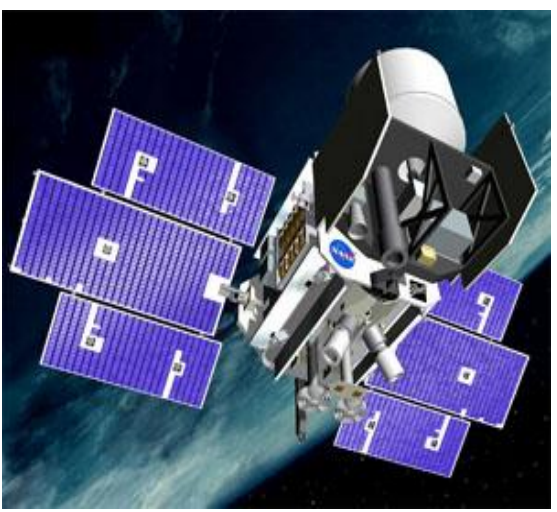

Figure 1: ICESAT/GLAS satellite (Figure courtesy: https://icesat.gsfc.nasa.gov/icesat/spacecraft.php)

The main instrument on ICESat is Geoscience Laser Altimeter System (GLAS) with three lasers. The orbital altitude of ICESat is $600 \mathrm{~km}$ with an inclination 94 degree and 183 day repeat pattern. GLAS is the first laser ranging instrument which enabled the continuous global observation of Earth. GLAS was successfully launched on January 12, 2003 abroad the ICESat from VanderBerg Air force Base. National Aeronautics and Space Administration (NASA) Goddard Space Flight Centre (GSFC) designed and implement the measurement instrument GLAS. The term altimetry is used for the range measurement to the earth surface. The three lasers namely laser1, laser2 and laser3 were mounted on a rigid optical bench with one laser operating at a time producing a $1024 \mathrm{~nm}$ pulse. The first laser operated from February 20, 2003 but failed on March 29, 2003. It had 119 equally spaced ground tracks to cover the earth with 8 day repeat orbit. Laser 2 also stopped working on October 2009 due to the energy loss caused by photo darkening near the laser frequency doubler. Laser 3 worked for 14 days and stopped working in October 2008.ICESat carried about 18 laser campaigns and remained seven years in orbit. [3], [4], [5], [6], [7]. Figure 2 illustrates how the GLAS instruments on Earth surface.

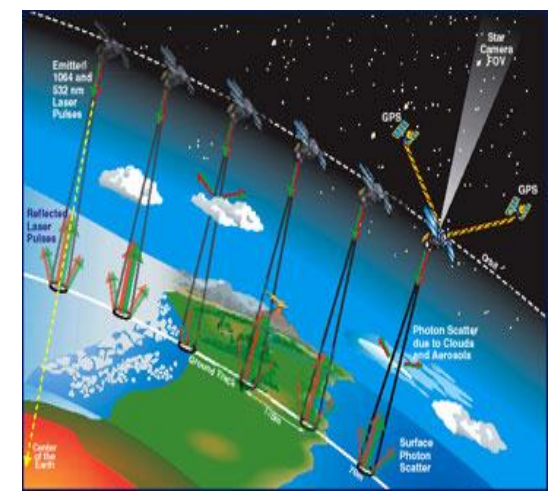

Figure 2: Schematic illustration of the GLAS instrument making measurement from ICESat while orbiting the Earth. (Figure courtesy: https://attic.gsfc.nasa.gov/glas/about.html)

GLAS operates with infrared and visible light pulses at $532 \mathrm{~nm}$ and $1064 \mathrm{~nm}$ wavelengths at eye safe signal levels. GLAS consisted of a laser system to measure distance, a GPS receiver (Global positioning system) and a star tracker attitude determining system. The laser transmits shot pulses (4ns) of infrared light (1064nm wavelength) and visible green light $(532 \mathrm{~nm})$. Photons reflected to the space craft from the surface of the earth and from the atmosphere, clouds etc were received by a telescope having diameter $1 \mathrm{~m}$ to collect the reflected $1064 \mathrm{~nm}$ laser light. Laser pulses were emitted at 40 times per second with pulses from NDYAG laser having footprints of diameter $70 \mathrm{~m}$ and separated by $170 \mathrm{~m}$ (560ft). The reflected photons were directed to an analogue digitizer and the digitized pulses are called laser waveforms. The time taken for sending and the receiving were computed, and pulse time of flight can be computed. Speed of light multiplied with half the time of flight generated the magnitude of the range vector [8], [9], [10]. The direction of the range vector from ICESat GLAS can be obtained from the Instrument Star Tracker (IST) and Hemispherical Resonator Gyroscope (HRS). Precision attitude determination (PAD) and precision orbit determination can be made in the instrument. The application of ICESat extends from cryosphere applications to numerous multidisciplinary applications. The elevation of the spot illuminated by the laser pulse is taken as the sum of the position vector and range vector which is the footprint giving latitude, longitude and height with respect to the reference ellipsoid. ICESat also provided information on the global distribution of clouds and aerosols. Laser energy emitted by GLAS have wavelength values $1064 \mathrm{~nm}$ and $532 \mathrm{~nm}$.GLAS can measure precisely the time taken for the photons to pass through the atmosphere, 


\section{Available online at www.ijrat.org}

reflected off the surface or clouds, collected in the GLAS telescope. The distance from the ICESat to the laser footprint in Earth's surface can be obtained from the total travel time and the speed of light. The location of ICESat is tracked by the GPS receiver. For calculating the elevation and position of each point measurement on the Earth, the data including distance to the laser footprint on the surface, position of the satellite in space, and the pointing of the laser are all combined.

(https://attic.gsfc.nasa.gov/glas/docs/ICESat_Broch ure.pdf).

\section{DATA PRODUCTS}

ICESat provided multiyear elevation data from 2003 to 2009 and covers the Earth from 86 Degree north to 86 Degree South. GLAS provided 15 data products including level L1A, L1B and L2 laser altimetry and atmospheric LiDAR data. The data products range from GLA01, GLA02, GLA03, etc to GLA15 and is given in the Table 1.

\begin{tabular}{|c|c|}
\hline ID & GLAS data \\
\hline GLA01 & Altimetry Data \\
\hline GLA02 & Atmospheric data \\
\hline GLA03 & Engineering data \\
\hline GLA04 & LPA-LRS data \\
\hline GLA05 & $\begin{array}{l}\text { Waveform based elevations } \\
\text { corrections }\end{array}$ \\
\hline GLA06 & Elevation \\
\hline GLA07 & Backscatter \\
\hline GLA08 & $\begin{array}{l}\text { Boundary layer and Elevated } \\
\text { Aerosol Layer heights }\end{array}$ \\
\hline GLA09 & $\begin{array}{l}\text { Cloud heights for multiple } \\
\text { layers }\end{array}$ \\
\hline GLA10 & Aerosol vertical structure \\
\hline GLA11 & $\begin{array}{lll}\text { Thin cloud/Aerosol optical } & \text { ol } \\
\text { depth } & & \end{array}$ \\
\hline GLA12 & Elevations ice sheet \\
\hline GLA13 & Elevations sea ice \\
\hline GLA14 & Elevations land \\
\hline GLA15 & Elevations Oceans \\
\hline
\end{tabular}

Table 1: 15 Data Products of GLAS
Level 1A altimetry data (GLA01) contains transmitted and received waveforms from the altimeter. GLA02 Level 1A atmospheric data contains the normalised relative backscatter for the $532 \mathrm{~nm}$ and $1064 \mathrm{~nm}$ channels; and low level instrument corrections such as laser energy, photon coincidence and detector gain corrections. GLA04 Level 1A global laser pointing data contain 20 orbits of attitude data from the spacecraft star tracker instrument star tracker and laser reference system, and other spacecraft attitude data required to calculate precise laser pointing. GLA05 level 1B waveform data include output parameters from the waveform characterisation procedure and other parameters required to calculate surface slope and relief characteristics. GLA06 Level 1B Global elevation product contains elevation previously corrected for tides, atmospheric delays and surface characteristics within the footprints. GLA07 level 1B global backscattering data are provided at full instrument resolution. The product includes full $532 \mathrm{~nm}$ and $1064 \mathrm{~nm}$ calibrated attenuated backscattering profiles at 5 times per second and from 10 to $1 \mathrm{~km}$ at 40 times per second for both channels. GLA08 level 2 planetary boundary layer (PBL) heights ground detection heights, top and bottom heights of elevated aerosols from $-1.5 \mathrm{~km}$ to $20.5 \mathrm{~km}$ and $20.5 \mathrm{~km}$ to $41 \mathrm{~km}$. GLA09 level 2 cloud height for multilayer clouds contain cloud layer top and bottom height data at sampling rates of $4 \mathrm{sec}$, $1 \mathrm{sec}, 5 \mathrm{~Hz}, 40 \mathrm{~Hz}$. GLA10 level 2 aerosol vertical structure data contains the attenuation corrected cloud and aerosol backscatter and extinction profiles at a $4 \mathrm{sec}$ sampling rate for aerosols and a $1 \mathrm{sec}$ rate for clouds. GLA 11 level 2 thin cloudlaerosol optical depths data contain thin cloud and aerosol optical depths. A thin cloud is one that does not completely attenuate the LiDAR signal return which generally corresponds to clouds with depths less than about 2.0. GLA 06 is used in conjunction with GLA05 to create the level 2 altimetry products. Level 2 altimetry data provide surface elevation for ice sheets GLA12, sea ice GLA13, landGLA14 and oceans GLA15. ICESat data are distributed by National Snow and Ice Data Centre (NSIDC).

GLAS data products can be downloaded freely from NSIDC website. They were in binary format up to August 2017. From August 2017, all the GLAS data are provided in HDF5 format. 
ICESat profiles provides a global sampling of the elevation of the Earth land surface with unprecedented accuracy which can be used as a framework to evaluate and improve the accuracy of topographic maps acquired by other airborne and space borne remote sensing methods. It enabled the direct observation of topographic changes and provided unique information about the height dimension of the surface features within each laser foot print. The elevation of the ground and the height, density of the vegetation cover can be inferred from the return pulse. The vegetation information from ICESat enable estimation of above ground biomass and its loss due to deforestation which is an important link of carbon cycle.

\section{APPLICATIONS OF ICESat GLAS IN FORESTRY}

Three dimensional measurements of forest canopies play a significant role in the global carbon dynamics and biomass estimation. It is very essential to obtain the vertical distribution and structure of the forest canopies for understanding the forest ecosystem dynamics. Traditional field inventories are time consuming, laborious as well as cover only limited areas. Passive optical remote sensing technologies are limited to provide only the horizontal distribution of forest. ICESat can retrieve the forest canopy height in global level. Several studies have reported successful results of forest measurements by utilizing GLAS data. A few of the studies for estimating certain forests parameters are briefed below.

\subsection{Canopy height estimation and canopy height modelling using GLAS ICESat.}

Forest structural retrieval studies were done by many researchers by exploring GLAS data. ([11], [12], [13], [14], [15]. In earlier studies direct estimation of the canopy heights were done which was the difference between the vertical signal start of the GLAS waveforms and the ground peak [16], [17]. The signal start indicates the top of the canopy. But severe fluctuations limit the availability of accurate signal start and peaks and to reimburse the limitations several studies utilized Gaussian decomposition methods [16], [17] [18], [19]. But the number of Gaussian peaks increase with topographic variation and heterogeneity in vegetation [20].
The application of GLAS data set for forest monitoring and mensuration by the estimation of maximum canopy heights of Korean forests were elucidated by [21]. A new automated method of canopy height estimation was also proposed [22]. Canopy heights extraction from GLAS were found to be varied with [23]. Two methods direct and statistical methods are used for extracting canopy height estimates from GLAS data [14], [24]. Canopy heights were estimated by using GLAS ICESat waveform data [11]. Other methods like Gaussian components approach by fitting it to raw waveform [25] and least square regression approaches [26] were also explored for estimation of forest structural details. Multiple linear regressions and the Random Forest technique (RF) were used for estimating canopy heights using GLAS data in French Guiana [27]. GLAS LiDAR derived Global estimates of canopy heights from 2004-2008 were provided by [28]. Canopy heights were estimated from the GLAS data using error factor analysis in Hoikkodo, Japan [29]. Canopy heights were estimated by using Lorey's height with the help of GLAS data and optical imagery over Hyrcanian forests of Iran [30]. Canopy heights were estimated over sloped terrain by [31].

\subsection{Biomass estimation using GLAS}

Quantifying above ground biomass in forests has profound social and economic interests and to estimate carbon emissions. In high biomass areas, the space borne ICESat GLAS data were used for effectively estimating biomass [32]. In some studies, biomass was estimated by using GLAS metrics interpolations [33]. Forest canopy heights and above ground biomass were estimated by means of GLAS data [11] and by means of GLAS and SRTM data [34]. In Quebec provincial forest, Canada, resources including biomass were estimated by developing an equation relating airborne laser estimates of biomass to ICESat/GLAS measurements [35]. Genetic Algorithm Approach for Optimization of Biomass Estimation using GLAS data were also found to be explored [36]. Annual changes in biomass were found to be estimated by combining ICESat GLAS waveform, historical inventory data and time series optical and radar imagery in China [37]. In several studies, GLAS data and other spectral data were integrated to obtain more biophysical parameters of forests. For example, above ground biomass 
mapping were done by MODIS and ICESat GLAS waveform in China [38]. Estimation of forest biomass in Changbai mountain region were done by using ICESat GLAS and Landsat/TM [39].

Various other forest parameters can be estimated by using GLAS data. Timber volume were estimated by the GLAS and MODIS data [40]. Three dimensional mapping of the mangrove forests were done using GLAS ICESat data [41] Vegetation vertical structure were estimated by means of GLAS wave form measurements [23]. Based on gap fraction model, Leaf area index were retrieved in discontinuous forests by means of GLAS ICESat waveform data [42]. GLAS data proved to capture the vertical structures of forest globally and applicable for forest parameter estimation and monitoring.

\section{ICESat -2 MISSION}

ICESat -2 was launched on September 15, 2018, a mission which measure heights, vegetation distribution across worldwide forests, heights across tropical and temperate regions of Earth along with other main applications. ICESat-2 carries a single instrument called Advanced topographic Laser Altimeter system and it measures the travel time of the laser pulses between the space crafts and Earth surfaces (ICESat2.gsfc.nasa.gov). The Laser light is of $532 \mathrm{~nm}$ and sends 10, 000 pulses per sec which is at an incredible fast rate and can take measurements at every 2.3 feet along the satellite's ground path. ICESat-2 will provide accurate information on large scale vegetation biomass estimates by measuring vegetation canopy heights [7]. ICESat-2 can map forest productivity, forest height which is further appropriate for carbon management.

\section{CONCLUSION}

ICESat GLAS operations, data products and its application are briefly reviewed in the given paper. The application of ICESat GLAS in forestry for various vertical structural parameters were given in the review. Regional and national level forest monitoring programs can be informed using the application of space borne laser altimetry in reliable manner. Also, space borne data can be integrated with other satellite sensor imageries to extract wide range of forest parameters. The space borne laser altimetry measurements can be used as an integral component of forest monitoring system. Thus, space borne GLAS can be used to represent the forest ecosystem and conditions in a timely and cost effective manner globally.

\section{ACKNOWLEGEMENT}

The first author is supported by Kerala State Council for Science Technology and Environment (KSCSTE), Thiruvananthapuram, India (Grant No:042/FSHP-ENV/2015/KSCSTE) in the form of a fellowship for doctoral research. Special thanks to National Snow and Ice Data Centre (NSIDC) for providing with the information.

\section{REFERENCES}

[1] Zwally, H. J., Schutz, B., Abdalati, W., Abshire, J., Bentley, C., Brenner, A., ... \& Herring, T. (2002). ICESat's laser measurements of polar ice, atmosphere, ocean, and land. Journal of Geodynamics, 34(3), 405445.

[2] Zwally, H. J., Schutz, R., Bentley, C., Bufton, J., Herring, T., Minster, J., ... \& Thomas, R. (2010). GLAS/ICESat L2 Antarctic and Greenland ice sheet altimetry data V031. National Snow and Ice Data Center, Boulder, Colorado.

[3] Abshire, J. B., Sun, X., Riris, H., Sirota, J. M., McGarry, J. F., Palm, S., ... \& Liiva, P. (2005). Geoscience laser altimeter system (GLAS) on the ICESat mission: on-orbit measurement performance. Geophysical Research Letters, 32(21).

[4] Schutz, B. E. (1998). Spaceborne laser altimetry: 2001 and beyond. Book of Extended Abstracts, edited by: Plag, HP, WEGENER-98, Norwegian Mapping Authority, Honefoss, Norway.

[5] Kichak, R. A. (2003). Independent GLAS anomaly review board executive summary. Goddard Space Flight Center, Greenbelt, Maryland, USA, ICESat Website: http://icesat. gsfc. nasa. gov/docs/IGARB. pdf, 11(04).

[6] Allan, G. R. (2008, May). Evidence for optically induced heating of the GLAS/ICESAT doubler crystal. In Conference on Lasers and Electro-Optics (p. CFQ7). Optical Society of America.

[7] Abdalati, W., Zwally, H. J., Bindschadler, R., Csatho, B., Farrell, S. L., Fricker, H. A., ... \& Marshak, A. (2010). The ICESat-2 laser altimetry mission. Proceedings of the IEEE, 98(5), 735-751.

[8] Schutz, B. E., Zwally, H. J., Shuman, C. A., Hancock, D., \& DiMarzio, J. P. (2005). Overview of the ICESat mission. Geophysical Research Letters, 32(21). 
[9] Wang, X., Cheng, X., Gong, P., Huang, H., Li, Z., \& Li, X. (2011). Earth science applications of ICESat/GLAS: a review. International Journal of Remote Sensing, 32(23), 88378864.

[10] Schutz, B. E. (2002). Laser footprint location (geolocation) and surface profiles. Geoscience laser altimeter system (GLAS): algorithm theoretical basis document version, 3, 11-19.

[11] Lefsky, M. A., Harding, D. J., Keller, M., Cohen, W. B., Carabajal, C. C., Del Bom Espirito-Santo, F., ... \& de Oliveira, R. (2005). Estimates of forest canopy height and aboveground biomass using ICESat. Geophysical research letters, 32(22).

[12]Lefsky, M. A., Keller, M., Pang, Y., De Camargo, P. B., \& Hunter, M. O. (2007). Revised method for forest canopy height estimation from Geoscience Laser Altimeter System waveforms. Journal of Applied Remote Sensing, 1(1), 013537.

[13] Duong, V. H., Lindenbergh, R., Pfeifer, N., \& Vosselman, G. (2008). Single and two epoch analysis of ICESat full waveform data over forested areas. International Journal of Remote Sensing, 29(5), 1453-1473.

[14] Rosette, J. A. B., North, P. R. J., \& Suarez, J. C. (2008). Vegetation height estimates for a mixed temperate forest using satellite laser altimetry. International Journal of Remote Sensing, 29(5), 1475-1493.

[15] Sun, G., Ranson, K. J., Kimes, D. S., Blair, J. B., \& Kovacs, K. (2008). Forest vertical structure from GLAS: An evaluation using LVIS and SRTM data. Remote Sensing of Environment, 112(1), 107-117.

[16] Hofton, M. A., Minster, J. B., \& Blair, J. B. (2000). Decomposition of laser altimeter waveforms. IEEE Transactions on geoscience and remote sensing, 38(4), 1989-1996.

[17] Neuenschwander, A. L., Urban, T. J., Gutierrez, R., \& Schutz, B. E. (2008). Characterization of ICESat/GLAS waveforms over terrestrial ecosystems: Implications for vegetation mapping. Journal of Geophysical Research: Biogeosciences, 113(G2).

[18]Chen, Q. (2010). Assessment of terrain elevation derived from satellite laser altimetry over mountainous forest areas using airborne LiDAR data, ISPRS Journal of Photogrammetry and Remote Sensing, Vol. 65, pp. 111-122.

[19] Chen, Q. (2010). Retrieving vegetation height of forests and woodlands over mountainous areas in the Pacific Coast region using satellite laser altimetry. Remote Sensing of Environment, 114(7), 1610-1627.
[20]Duncanson, L. I., Niemann, K. O., \& Wulder, M. A. (2010). Integration of GLAS and Landsat TM data for aboveground biomass estimation. Canadian Journal of Remote Sensing, 36(2), 129-141.

[21] Park, T. J., Lee, W. K., Lee, J. Y., Hayashi, M., Tang, Y., Kwak, D. A., ... \& Nam, K. J. (2012). Maximum canopy height estimation using ICESat GLAS laser altimetry. Korean Journal of Remote Sensing, 28(3), 307-318.

[22] Iqbal, I. A., Dash, J., Ullah, S., \& Ahmad, G. (2013). A novel approach to estimate canopy height using ICESat/GLAS data : a case study in the New Forest National Park, UK. International Journal of Applied Earth Observation and Geoinformation (JAG), 23, 109-118. https://doi.org/10.1016/j.jag.2012.12.009

[23] Harding, D. J., \& Carabajal, C. C. (2005). ICESat waveform measurements of withinfootprint topographic relief and vegetation vertical structure. Geophysical research letters, 32(21).

[24]Pang, Y., Lefsky, M., Sun, G., Miller, M. E., \& Li, Z. (2008). Temperate forest height estimation performance using ICESat GLAS data from different observation periods. International Archives of the Photogrammetry, Remote Sensing and Spatial Information Sciences, 37(Part B7), 777-782.

[25] Brenner, A. C., Zwally, H. J., Bentley, C. R., Csatho, B. M., Harding, D. J., Hofton, M. A., ... \& Yi, D. (2012). The algorithm theoretical basis document for the derivation of range and range distributions from laser pulse waveform analysis for surface elevations, roughness, slope, and vegetation heights.

[26] Markwardt, C. B. (2009). Non-linear least squares fitting in IDL with MPFIT. arXiv preprint arXiv:0902.2850.

[27] Fayad, I., Baghdadi, N., Bailly, J. S., Barbier, N., Gond, V., El Hajj, M., \& Fabre, F. (2014, July). Canopy height estimation in French Guiana using LiDAR ICESat/GLAS data. In Geoscience and Remote Sensing Symposium (IGARSS), 2014 IEEE International (pp. 13371340). IEEE.

[28] Healey, S.P., M.W. Hernandez, D.P. Edwards, M.A. Lefsky, E. Freeman, P.L. Patterson, E.J. Lindquist, and A.J. Lister. 2015. CMS: GLAS LiDAR-derived Global Estimates of Forest Canopy Height, 2004-2008. ORNL DAAC, Oak Ridge, Tennessee, USA. http://dx.doi.org/10.3334/ORNLDAAC/1271

[29] Hayashi, M., Saigusa, N., Oguma, H., \& Yamagata, Y. (2013). Forest canopy height estimation using ICESat/GLAS data and error factor analysis in Hokkaido, Japan. ISPRS 


\section{Available online at www.ijrat.org}

journal of photogrammetry and remote sensing, 81, 12-18.

[30] Rajab Pourrahmati, M., Baghdadi, N., Darvishsefat, A. A., Namiranian, M., Gond, V., Bailly, J. S., \& Zargham, N. (2018). Mapping Lorey's height over Hyrcanian forests of Iran using synergy of ICESat/GLAS and optical images. European Journal of Remote Sensing, 51(1), 100-115.

[31] Xing, Y., de Gier, A., Zhang, J., \& Wang, L. (2010). An improved method for estimating forest canopy height using ICESat-GLAS full waveform data over sloping terrain: A case study in Changbai mountains, China. International journal of applied earth observation and geoinformation, 12(5), 385392.

[32]Hajj, M. E., Baghdadi, N., Fayad, I., Vieilledent, G., Bailly, J. S., \& Minh, D. H. T. (2017). Interest of integrating spaceborne LiDAR data to improve the estimation of biomass in high biomass forested areas. Remote Sensing, 9(3), 213.

[33] Hu, T., Su, Y., Xue, B., Liu, J., Zhao, X., Fang, J., \& Guo, Q. (2016). Mapping global forest aboveground biomass with spaceborne LiDAR, optical imagery, and forest inventory data. Remote Sensing, 8(7), 565.

[34] Fatoyinbo, T. E., \& Simard, M. (2013). Height and biomass of mangroves in Africa from ICESat/GLAS and SRTM. International Journal of Remote Sensing, 34(2), 668-681.

[35] Nelson, R., Boudreau, J., Gregoire, T. G., Margolis, H., Næsset, E., Gobakken, T., \& Ståhl, G. (2009). Estimating Quebec provincial forest resources using ICESat/GLAS. Canadian Journal of Forest Research, 39(4), 862-881.

[36] Jain, A. (2019). Genetic Algorithm Approach for Optimization of Biomass Estimation at LiDAR. In Data Science and Big Data Analytics (pp. 11-27). Springer, Singapore.

[37] Shen, W., Li, M., Huang, C., Tao, X., \& Wei, A. (2018). Annual forest aboveground biomass changes mapped using ICESat/GLAS measurements, historical inventory data, and time-series optical and radar imagery for Guangdong province, China. Agricultural and Forest Meteorology, 259, 23-38.

[38] Chi, H., Sun, G., Huang, J., Guo, Z., Ni, W., \& $\mathrm{Fu}$, A. (2015). National forest aboveground biomass mapping from ICESat/GLAS data and MODIS imagery in China. Remote Sensing, 7(5), 5534-5564.

[39] Chi, H., Sun, G., Huang, J., Li, R., Ren, X., Ni, W., \& Fu, A. (2017). Estimation of forest aboveground biomass in Changbai mountain region using ICESat/GLAS and Landsat/TM data. Remote Sensing, 9(7), 707.

[40]Nelson, R., Ranson, K. J., Sun, G., Kimes, D. S., Kharuk, V., \& Montesano, P. (2009). Estimating Siberian timber volume using MODIS and ICESat/GLAS. Remote Sensing of Environment, 113(3), 691-701.

[41]Simard, M., Rivera-Monroy, V. H., Mancera-Pineda, J. E., Castañeda-Moya, E., \& Twilley, R. R. (2008). A systematic method for 3D mapping of mangrove forests based on Shuttle Radar Topography Mission elevation data, ICESat/GLAS waveforms and field data: Application to Ciénaga Grande de Santa Marta, Colombia. Remote Sensing of Environment, 112(5), 2131-2144.

[42] Yang, X., Wang, C., Pan, F., Nie, S., Xi, X., \& Luo, S. (2019). Retrieving leaf area index in discontinuous forest using ICESat/GLAS full-waveform data based on gap fraction model. ISPRS Journal of Photogrammetry and Remote Sensing, 148, 54-62. 